\title{
The importance of prey densities and background plankton in studies of predation on invertebrate larvae
}

\author{
Kevin B. Johnson*, Alan L. Shanks \\ Oregon Institute of Marine Biology, Charleston, Oregon 97420, USA
}

\begin{abstract}
Laboratory experiments investigating predation by plankton on meroplanktonic invertebrate larvae often use unnaturally high densities of prey in filtered seawater. Offering prey under these conditions, however, can alter predator behavior and capture success, potentially creating artifactual predator-prey relationships and predation rates. We conducted laboratory experiments investigating the effect of a range of larval invertebrate densities on predation rates. For the 4 predator-prey combinations examined, there was no predation at natural prey densities in filtered seawater. We then conducted predator-prey experiments in the presence and absence of naturally occurring ambient plankton ('background plankton') at densities where predation had been observed in filtered seawater. In most experiments, background plankton dramatically decreased or eliminated predation which had been observed with unnaturally high prey densities in filtered seawater.
\end{abstract}

KEY WORDS: Meroplankton - Invertebrate larvae - Predation Background plankton - Prey density

Laboratory experiments investigating predation upon meroplanktonic invertebrate larvae are often conducted using unnaturally high densities of meroplanktonic prey in filtered seawater. Unnaturally high prey densities can alter predator behavior, capture success, and food preference. These density effects have been observed in other predator-prey systems (e.g. Holling 1959, Krebs et al. 1977). To the best of our knowledge, however, this is the first study directly examining the influence of prey densities on predation of invertebrate larvae by planktonic predators.

Using filtered seawater for laboratory predation experiments, like using unnaturally high prey densities, may also induce unnatural predation. Planktonic predators may be generalists, feeding upon all poten-

\footnotetext{
-E-mail:kbj@darkwing.uoregon.edu
}

tial prey, including the naturally occurring ambient plankton ('background plankton'). Background plankton, including protists and phytoplankton, are far more abundant than relatively rare meroplanktonic invertebrate larvae. By occupying or satiating the predator, or obscuring larvae from detection, background plankton may reduce larval predation. Alternatively, predators may specialize in feeding on prey other than the type being offered. In either case, predators consuming prey in filtered seawater may not do so in the presence of background plankton.

We conducted predation experiments, observing predation rates, in filtered seawater over a range of prey densities, including near-natural and unnaturally high densities. Using prey densities where predation was observed in filtered seawater, we then conducted predation experiments with and without background plankton.

Methods. Three predators (the zoea of the mud shrimp Upogebia pugettensis, the leptomedusa Obelia sp., and an unidentified leptomedusa) and 3 prey types (blastulae and plutei of the purple sea urchin Strongylocentrotus purpuratus, and barnacle nauplii) were used to create 4 predator-prey combinations. Some zoeae and hydromedusae are known to be predatory (e.g. Rumrill 1987), but no information is available on the natural prey of our selected predatory species. $S$. purpuratus were spawned and maintained using standard techniques (Strathmann 1987). Blastulae were approximately $120 \mu \mathrm{m}$ long and plutei were 4 -arm stage and approximately $200 \mu \mathrm{m}$ in length. Barnacle nauplii (body length 200 to $250 \mu \mathrm{m}$ ) and all predators were collected at high tide from near the mouth of

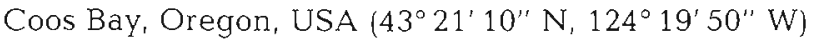
by slowly towing a plankton net equipped with a large blind cod-end (after Reeve 1981). Experiments began within $24 \mathrm{~h}$ of predator collection and were conducted on a roller table (Omori \& Ikeda 1984, Larson \& Shanks 
1996), which rolled 3 I cylindrical tanks at $1 \mathrm{rpm}$ and prevented plankton from settling Though enclosed, plankton do not suffer oxygen depletion during the experimental time frame (Larson \& Shanks 1996). The roller table was maintained at $12^{\circ} \mathrm{C}$ in a constant temperature room with a 14:10 light:dark cycle for $24 \mathrm{~h}$. Observations of predators and prey in roller tanks revealed them to stay suspended in the water column and exhibit apparently normal behavior. At the end of each experiment, predators and remaining prey were collected, fixed, and counts of surviving larvae made using a compound microscope. 'Mortality' is based upon the lack of retrieval of whole, unconsumed larvae and the difference in mortality between treatments with and without predators is attributed to predation.

When treatments are stated to be different, we refer to $\alpha=0.05$ with the Games \& Howell (G\&H) mean significant difference method of a posteriori pairwise comparison of means (Sokal \& Rohlf 1995), performed after a significant Kruskal-Wallis ANOVA (K-W ANOVA). The G\&H method of comparing means is appropriate for heterogeneous variances and small sample sizes.

Prey density experiments: Experiments investigating the effect of variation in prey density on predation were conducted in $1 \mu \mathrm{m}$ filtered seawater with 4 different predator-prey combinations: mud shrimp zoea preying upon plutei, mud shrimp zoea preying upon blastulae, unidentified leptomedusa preying upon barnacle nauplii, and Obelia sp. medusa preying upon blastulae. Predator density was $1 \operatorname{tank}^{-1}$. Three replicate treatments (predators present) and controls (predators absent) were run for each prey density. Prey densities (Fig. 1) ranged from near-natural to unnaturally high densities. Published observations of larval urchin field densities (and, by extrapolation, conservative urchin blastula densities) range from 0.08 to $0.39 \mathrm{l}^{-1}$ (Zimmerman 1972, Cameron \& Rumrill 1982, Rumrill et al. 1985, Emlet 1986, Rumrill 1987) and the highest reported density is only $0.74 \mathrm{l}^{-1}$ (Miller 1995). Natural urchin densities are represented in our experiments as a density of $11^{-1}$ By contrast, densities of echinopluteus larvae used in past laboratory predation experiments has often ranged from 25 to $500 \mathrm{l}^{-1}$ (e.g. Rumrill et al. 1985, Pennington et al. 1986). Natural densities for barnacle nauplii may be as high as $15 \mathrm{l}^{-1}$ (Zimmerman 1972). Natural nauplius densities are represented in our experiments as densities of $1,3,5$, and $10 \mathrm{l}^{-1}$. Our high density of $50 \mathrm{l}^{-1}$ exceeds published observations and is intended to be unnaturally high. At the end of each experiment, predators and remaining prey were collected and fixed. Counts of surviving larvae were made using a compound microscope.

Background plankton experiments: Predation experiments with and without background plankton were conducted with 3 of the same predator-prey combinations used in the previous experiments. Experiments were run at prey densities at which predation was observed in the above-described prey density experiments (Fig. 2). Experiments with the Obelia sp. medusa preying upon blastulae and the unideritified leptomedusa preying upon barnacle nauplii consisted of 5 treatments, 3 replicates each, at each selected prey density. The 5 treatments were prey alone in filtered seawater, prey with a predator in filtered seawater, prey alone with background plankton, prey with a predator and background plankton, and larvae and background plankton fixed at the onset of the experiment (a control for retrieval artifacts in the presence of background plankton). The protocol for the experiment with the mud shrimp zoea preying upon plutei was the same as those described above, but lacked the background plankton control. Background plankton were obtained by col- 


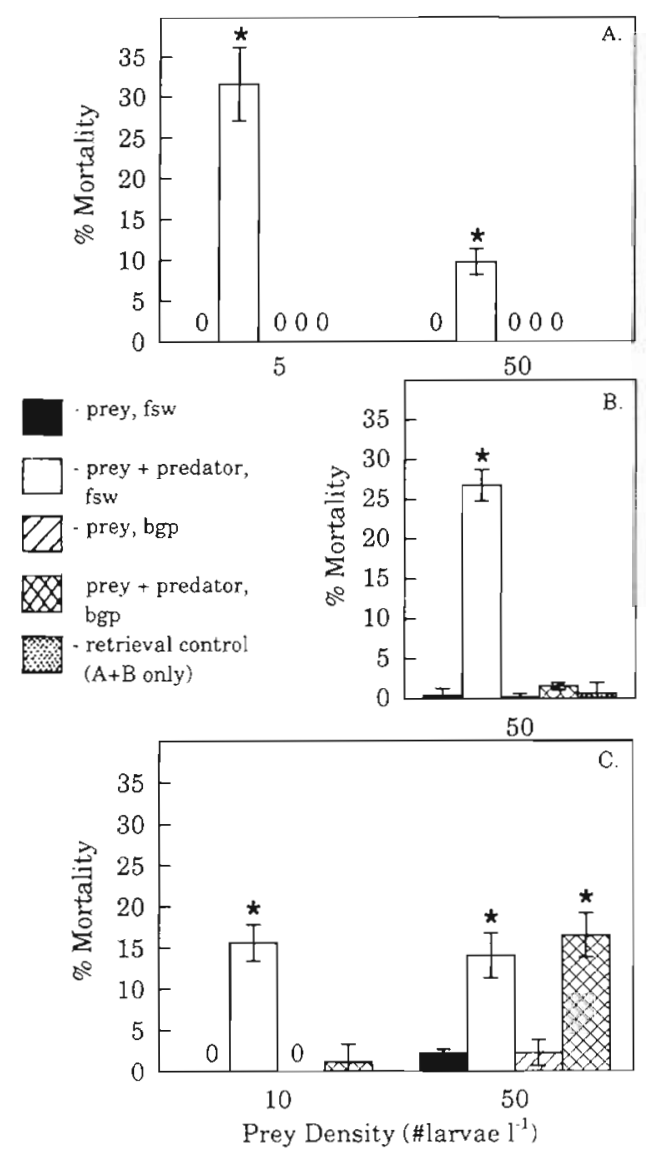

Fig. 2. For 3 predator-prey combinations, percent prey mortality at densities selected based upon observed predation in prey density experiments (see Fig. 1): (A) Obelia sp. preying upon blastulae; (B) unidentified leptomedusa preying upon barnacle nauplii; (C) mud shrimp zoea preying upon plutei. In (A) and (B), the 5 columns for each prey density (5 and 50 larvae $\mathrm{l}^{-1}$ ) are (left to right): prey in filtered seawater (fsw) prey and predator in fsw; prey and background plankton (bgp); prey and predator with bgp; prey and bgp fixed immediately (retrieval control). The 4 data columns for each prey density in (C) (10 and 50 larvae $\mathrm{l}^{-1}$ ) represent the first 4 treatments above. Columns with zero mean and variance are indicated by a ' 0 ' Error bars represent the $95 \%$ confidence interval. Treatments that are significantly different from their respective control at $\alpha=0.05$ are marked with a star

lecting whole seawater (unfiltered seawater with a natural composition and density of plankton) from near the mouth of Coos Bay at high tide.

Results. Prey density experiments: For all predatorprey combinations the percent predation varied with prey density. For the zoea preying upon plutei and blastulae, predation was significant only at prey densities of 10 and $50 \mathrm{l}^{-1}$ (Fig. 1A) and $50 \mathrm{l}^{-1}$ (Fig. 1B), respectively. With the unidentified leptomedusa as a predator on barnacle nauplii (Fig. 1C), significant predation was only observed at a prey density of $50 \mathrm{l}^{-1}$.
Significant predation was observed at prey densities of 50 and $83 \mathrm{I}^{-1}$ with Obelia sp. as the predator on blastulae (Fig. 1D).

Background plankton experiments: When Obelia sp. was a predator upon blastulae (Fig. 2A), mean mortalities of 31 and $10 \%$ were observed in filtered seawater at prey densities of 5 and $50 \mathrm{l}^{-1}$, respectively. When background plankton was present, however, mortality was completely eliminated at both of these prey densities. The primary components of background plankton in this experiment included 4 diatom species and the dinoflagellate Noctiluca scintillans. Background invertebrate larvae found in relatively low numbers included polychaete metatrochophores (Spionidae) and copepod nauplii. When background plankton and larvae were fixed immediately, the exact number of added blastulae were retrieved in all replicates, suggesting there were no wild blastulae in the background plankton medium. Only one prey density, $50 \mathrm{l}^{-1}$, was examined for the unknown leptomedusa preying upon barnacle nauplii (Fig. 2B). At this prey density, the mean mortality of $27 \%$ in filtered seawater was completely eliminated by the addition of background plankton. The primary components of background plankton in this experiment included 2 diatom species (different from species in the first background plankton experiment) and a variety of moderately abundant dinoflagellates. Pine pollen was also common in this background plankton. The number of barnacle nauplii retrieved when background and larvae were fixed immediately was exactly the number added in 2 of the replicates. In the third replicate, $98 \%$ of added barnacle larvae were recovered. As with blastulae, this suggests that there were no wild barnacle larvae in the size range of those used as prey. For the mud shrimp zoea preying on plutei (Fig. 2C) at a prey density of $10 \mathrm{l}^{-1}$, the presence of background plankton significantly reduced predation from an average of 16 to $1 \%$. At a prey density of $50 \mathrm{I}^{-1}$, however, the average predation in filtered seawater was 14 vs $17 \%$ in the presence of background plankton. Background plankton consisted of relatively abundant loricated ciliates, dinoflagellates of the genus Protoperidinium, and a wide variety of diatoms. This experiment lacked the treatment where background plankton and larvae were fixed immediately to control for artifacts. Retrieval of larvae with background plankton in the absence of a predator, however, was exactly $100 \%$ at $10 \mathrm{l}^{-1}$ and slightly less than $100 \%$ at $50 \mathrm{l}^{-1}$. Once again, this suggests that wild plutei were not added to the experiment by the use of background plankton. In all but this last predator-prey combination, background plankton reduced or eliminated predation.

Discussion. For all predator-prey combinations examined, predator-induced mortality tended to in- 
crease with prey density. Predation at natural prey densities was often nonexistent. The fact that predation tended to occur only at unnaturally high densities may be due to altered predator behavior, increased capture success at high densities, or may simply be the result of more frequent encounters with prey. Only in the latter case can predation rates at unnaturally high densities be extrapolated to the lower natural densities. Altered predator behaviors resulting from high densities of prey, such as prey switching and selectivity, and increased capture success (i.e. practice makes perfect) may be artifactually induced when unnaturally high prey densities are used. The mechanism underlying prey density's effect on predation rates has not been identified for these predator-prey combinations. Natural prey densities should be used to prevent behavioral artifacts from misleading investigators about the existence or strength of predator-prey relationships.

In all but one case, even when prey densities were unnaturally high, background plankton reduced or eliminated predation which had been observed in filtered seawater. Background plankton may serve as alternate food, occupying or satiating generalist predators. Background plankton may also obscure larvae from detection or hinder their capture. Whatever the mechanism, background plankton reduced the likelihood of these predators consuming meroplanktonic invertebrate larvae and embryos. Background plankton, a pervasive component of natural planktonic systems, should be present in laboratory investigations of planktonic predation.

Much of the information on predators of marine invertebrate larvae comes from laboratory experiments which have utilized unnaturally high prey densities and excluded background plankton. These experiments have contributed to the idea that predation in the plankton may be a major cause of larval mortality (Rumrill 1990, Morgan 1995). In this study we included natural prey densities and background plankton in an attempt to make our laboratory experiments more natural. We found that, under more natural conditions, predation was eliminated or greatly reduced. Perhaps previous laboratory experiments have given us a false impression of predation rates in the plankton.

Editorial responsibility: Joseph Pawlik (Contributing Editor), Wilmington, North Carolina, USA
Acknowledgements. This research was supported by NSF Grant OCE9521093. Colleen Johnson provided support and encouragement. This is a contribution from the Oregon Institute of Marine Biology, University of Oregon

\section{LITERATURE CITED}

Cameron RA, Rumrill SS (1982) Larval abundance and recruitment of the sand dollar Dendraster excentricus in Monterey Bay, California, USA Mar Biol 71:197-202

Emlet RB (1986) Larval production, dispersal, and growth in a fjord: a case study on larvae of the sand dollar Dendraster excentricus. Mar Ecol Prog Ser 31:245-254

Holling CS (1959) The components of predation as revealed by a study of small mammal predation of the European pine sawfly. Can Entomol 91:293-320

Krebs JR, Erichsen JT, Webber MI, Charnov EL (1977) Optimal prey-selection by the great tit (Parus major). Anim Behav 25:30-38

Larson ET, Shanks AL (1996) Consumption of marine snow by two species of juvenile mullet and its contribution to their growth. Mar Ecol Prog Ser 130:19-28

Miller B (1995) Larval abundance and early juvenile recruitment of echinoids, asteroids, and holothuroids on the Oregon coast. MS thesis, University of Oregon

Morgan SG (1995) Life and death in the plankton: larval mortality and adaptation. In: McEdward L (ed) Ecology of marine invertebrate larvae. CRC Press, New York

Omori M, Ikeda T (1984) Methods in marine zooplankton ecology. John Wiley \& Sons, New York

Pennington JT, Rumrill SS, Chia FS (1986) Stage-specific predation upon embryos and larvae of the pacific sand dollar, Dendraster excentricus, by 11 species of common zooplanktonic predators. Bull Mar Sci 39(2) 234-240

Reeve MR (1981) Large cod-end reservoirs as an aid to the live collection of delicate zooplankton. Limnol Oceanogr 26(3):577-580

Rumrill SS (1987) Differential predation upon embryos and larvae of Pacific echinoderms. PhD thesis, University of Alberta, Edmonton

Rumrill SS (1990) Natural mortality of marine invertebrate Iarvae. Ophelia $32(1-2): 163-198$

Rumrill SS, Pennington JT, Chia FS (1985). Differential susceptibility of marine invertebrate larvae: laboratory predation of sand dollar, Dendraster excentricus (Eschscholtz), embryos and larvae by zoeae of the red crab, Cancer productus (Randall). J Exp Mar Biol Ecol 90:193-208

Sokal RR, Rohlf FJ (1995) Biometry, 3rd edn. WH Freeman and Company, New York

Strathmann $M$ (1987) Reproduction and development of marine invertebrates of the Northern Pacific Coast. University of Washington Press, Seattle

Zimmerman ST (1972) Seasonal succession of zooplankton populations in two dissimilar marine embayments on the Oregon Coast. PhD thesis, Oregon State University

Submitted: July 31, 1997, Accepted: September 30, 1997 Proofs received from a uthor(s): November 4, 1997 